\title{
COMENTARIOS RESPECTO DE CESIONES DE DERECHOS
}

\author{
María Antonieta Medina Lebel \\ Egresada de Derecho \\ Universidad Gabriela Mistral
}

Estudiando materias para redactar mi memoria de prueba, he podido observar distintos criterios a aplicar para calificar cesiones de derechos respecto de bienes que se poseen en una comunidad de inmuebles hereditarios.

De allí nació mi interés en profundizar conceptos respecto de estas materias y ello, debo dejarlo en claro, respetando los criterios que pudieren expresar abogados más letrados en estas materias.

La duda jurídica que se presenta dice relación con los requisitos que se deben exigir para proceder a la cesión de derechos, (cuota), sobre un bien raíz hereditario y los necesarios para una disposición de un inmueble que ha sido adquirido por sucesión por causa de muerte, habiéndose practicado la inscripción especial de herencia.

Con relación a la disposición del inmueble hereditario, el artículo 688 del Código Civil establece los requisitos legales para ello, señalando que, una vez deferida la herencia, es decir, una vez abierta la sucesión, la posesión legal de ella se concede a los herederos por el sólo ministerio de la ley, pero dicha posesión no los habilita para disponer del inmueble hereditario. Para ello es necesario que preceda el decreto de posesión efectiva inscrito en el Registro de Propiedad del Conservador de Bienes Raíces de la comuna en que haya sido pronunciado y, además, las inscripciones especiales de herencia prevenidas en el artículo 687 inciso $1^{\circ}$ y $2^{\circ}$ del Código Civil.

En efecto, sin dejar de ser un bien hereditario, la citada inscripción especial de herencia respecto de un inmueble determinado, produce el efecto de sustituir al causante por sus herederos en el registro conservatorio, formándose entre éstos una comunidad regida, en todo, salvo determinadas excepciones, por las normas del cuasicontrato de comunidad previsto en los artículos 2.304 y siguientes del Código Civil.

Una vez practicadas dichas inscripciones, los herederos podrán disponer de consuno del inmueble.

En definitiva, podemos concluir que, para poder disponer del inmueble hereditario es necesario practicar la inscripción especial de herencia, pudiendo así los herederos efectuar actos de disposición, de común acuerdo. 
El problema se plantea respecto de la cesión de derechos sobre un inmueble adquirido por sucesión por causa de muerte.

Me tocó conocer un caso por el cual una persona adquirió a varios comuneros la totalidad de los derechos que cada uno de ellos tenía en un inmueble determinado, (recibidos por ellos por sucesión por causa de muerte, habiéndose tramitado la correspondiente posesión efectiva y efectuando la inscripción especial de herencia, pero sin haberse partido los bienes), consolidando así el dominio pleno sobre él. Esta adquisición la hizo suscribiendo varias escrituras públicas de cesión de derechos, de fechas distintas.

Como he dicho, cada uno de los cedentes había adquirido por sucesión por causa de muerte y practicado la inscripción especial de herencia respecto del inmueble cuyos derechos se cedieron.

En el citado caso, un abogado de una institución bancaria emitió un informe en el que señaló que no era posible efectuar cesiones de derechos respecto de bienes determinados, atendido lo dispuesto en el artículo 688 del Código Civil.

El texto de la parte pertinente del citado informe, que me permito copiar dice, textualmente, lo siguiente:

1.- Se observa que el adquirente ha pactado con los diferentes coherederos a fin de adquirir los derechos hereditarios de cada cual celebrando los tres contratos de que se habla precedentemente.

Las cesiones de derechos antes mencionadas contravienen en forma directa lo dispuesto en el artículo 688 del Código Civil, el cual previene en su numeral segundo que practicadas las inscripciones de posesión efectiva y especial de herencia, los herederos pueden disponer de consuno de los inmuebles hereditarios.

Hago presente que no se trata en cada caso de una cesión de todos los derechos que a cada uno de los herederos corresponde en las respectivas herencias de que se trata, lo cual es perfectamente posible. En el caso del estudio los herederos, individualmente, han cedido los derechos que pudieran tener en un inmueble determinado de la masa hereditaria. El artículo 688 del Código Civil, ya citado, dispone precisamente que, para disponer de inmuebles singulares de la masa hereditaria los herederos deben actuar de consuno, es decir conjuntamente y unánimemente.

La sanción aplicable a la infracción del precepto es un asunto muy discutido en nuestra doctrina. Las hipótesis modernas consideran la nulidad relativa, la inoponibilidad. Don Manuel Somarriva Undurraga, estima que la sanción consiste en que el adquirente queda sólo como poseedor del inmueble al no poder los herederos transferir el dominio por impedirlo el precepto del comentario." (fin de la cita).

Queriendo aportar opiniones al tema, me permito señalar al respecto: 
PRIMERO: Estimo que la situación jurídica relativa a un inmueble adquirido por sucesión por causa de muerte es distinta antes o después de la inscripción especial de herencia que se practica en el Registro de Propiedad del Conservador de Bienes Raíces respectivo, ya que, como dijimos anteriormente, dicha inscripción tiene por objeto que los herederos pasen a ser los propietarios de dichos inmuebles formándose una comunidad regida por las normas del cuasicontrato de comunidad, la que se forma por el sólo hecho de la muerte del causante;

SEGUNDO: Para los efectos de este comentario, a mi juicio, existe una coincidencia total entre las normas que rigen la comunidad formada por la vía de la sucesión por causa de muerte, con relación a la constituida por otros medios, ya que ambas están regidas por el denominado efecto declarativo de la partición, reglamentado por el artículo 1.344 del Código Civil, es decir, que efectuada que sea la partición, cada asignatario,(heredero), se reputará haber sucedido inmediata y exclusivamente al difunto desde el momento de la muerte. $Y$ haber adquirido el dominio de los efectos que se le adjudiquen en la sucesión desde dicho momento. Se estima que ese asignatario no tuvo jamás parte alguna en los otros efectos de la sucesión. ¿Qué significa esto? Si uno de los herederos enajena una cosa comprendida en la comunidad hereditaria y producida la partición no se le adjudica a él, sino a otro coasignatario, se procederá como en caso de venta de cosa ajena, concluyendo que el verdadero dueño, (asignatario al cual se le asignó la cosa), podrá intentar acción reivindicatoria, por ser dueño no poseedor.

El artículo 1.344 es ratificado por la norma del artículo 718 del mismo cuerpo legal inserto dentro de las normas de la posesión.

CUARTO: De ser así, adquieren plena vigencia las normas de los artículos $1.320 \mathrm{y}$ 1.812 del Código Civil, que rezan a la letra:

Artículo 1.320: "Si un coasignatario vende o cede su cuota a un extraño, tendrá éste igual derecho que el vendedor o cedente para pedir la participación e intervenir en ella".

Artículo 1.812: "Si la cosa es común de dos o más personas proindiviso, entre las cuales no intervenga contrato de sociedad, cada una de ellas podrá vender su cuota, aún sin el consentimiento de las otras".

Como consecuencia que la comunidad hereditaria se encuentra regida por las normas del cuasicontrato de comunidad, en la cual cada comunero tiene libertad para vender o ceder su cuota a un extraño, podemos concluir que en el caso de la comunidad formada por la muerte del causante, se produce la misma situación, es decir, cada coasignatario es dueño exclusi- 
vo de su cuota que le corresponda en el bien raíz hereditario y, como propietaria, puede disponer con plena libertad de los derechos que le corresponden en él.

Concluyendo este aspecto, podemos señalar que el verdadero alcance del artículo 688 del Código Civil, se refiere a la restricción de disposición del inmueble, pero no a los derechos constituidos sobre él. Esta distinción, es decir, la relativa a la posibilidad de disposición sobre el inmueble en su totalidad o sobre derechos de él, ha sido plenamente reconocida por los Conservadores de Bienes Raíces en el sentido que se admiten cesiones de derechos, practicadas que sean las inscripciones especiales de herencia, pero sin el pago del impuesto, pero no así las ventas de inmuebles, sin haberse cumplido con todas las inscripciones detalladas en el artículo 688 .

QUINTO: Examinando la normativa de la cesión de derechos de herencia, (contemplada en los artículos 1.909 y siguientes del Código Civil), podemos observar que las reglas que se contemplan respecto de esta materia son distintas a las que reglamentan la cesión de créditos.

Profundizando esta idea, y comparando conceptos, debemos decir que el objeto de la cesión del derecho de herencia es la entrega a un tercero de la universalidad de ellos o la cuota que al cedente corresponde en el conjunto de bienes que comprende el haber hereditario, de tal manera que los bienes individualmente determinados no pueden ser objeto de esta cesión.

Por su parte, la cesión de derechos es la entrega de éstos a un tercero sobre una porción intelectual de un bien determinado.

Si de alguna manera asimilamos la cesión de derechos a la compraventa, podemos observar que no son sinónimos, ni de igual carácter jurídico, los contratos de cesión de derechos hereditarios y el de compraventa.

Por otra parte, es interesante precisar que en la cesión de los derechos hereditarios el cedente se compromete sólo a que tiene la calidad de heredero en tanto que en la cesión de derechos debe responder por lo efectivamente cedido. Consecuencia de lo anterior es el de que la venta de derechos hereditarios es un contrato aleatorio, de incierta contingencia de ganancia o pérdida para el cesionario, atendida la circunstancia de que de lo único de que se hace responsable el vendedor o cedente es de su calidad de heredero. (Interesantes son las conclusiones jurisprudenciales que aparecen reproducidas en el Repertorio analizando el artículo 1.907 del Código Civil, y

SEXTO: Por último, no podemos dejar de mencionar que el artículo 54 de la Ley 16.271, de Impuesto a las Herencias y Donaciones, no obliga a acreditar el 
pago del impuesto de herencia en el caso de cesión de derechos hereditarios, lo que si es necesario en el caso de la cesión de derechos o la venta de un inmueble hereditario.

En consecuencia, mi opinión es que es legalmente factible hacer cesiones de derechos respecto de un bien determinado en el caso de comunidades formadas por sucesión por causa de muerte, ya practicadas las inscripciones especiales de herencia. Antes de practicar esta inscripción no es posible hacer la cesión de derechos en bienes determinados.

El cesionario de dichos derechos los adquiere bajo la condición prevista en el artículo 1.344 del Código Civil.

La opinión que estoy indicando se encuentra refrendada por don Manuel Somarriva Undurraga en su obra Indivisión y Partición. (Ed.Jur. de Chile, 1956), quien trata separadamente la "Cesión de la cuota parte o cesión de los derechos hereditarios" y la "cesión de cuota en un bien determinado."

Esta opinión se encuentra expresamente corroborada en la obra "Curso de Derecho Civil", (basado en la explicaciones de los profesores Arturo Alessandri R. y Manuel Samarriva Undurraga), redactado por don Antonio Vodanovic H., (Edt. Nascimiento, 1957, Tomo II, Pág.419), que señala textualmente: "Distinción entre la enajenación de bienes "determinados" de la herencia y la enajenación de ésta o de una cuota en ella". Es previo dejar establecido que la situación que vamos a analizar se refiere a la venta o cesión de los derechos hereditarios en la universalidad de la sucesión o en una cuota de ella, y no a la venta de los derechos hereditarios que al heredero vendedor o cedente corresponda en un bien determinado de la sucesión, porque en este último caso lo que se cede o vende es simplemente el bien raíz o una cuota en él, y es evidente que en tal caso la inscripción es la única forma de hacer la tradición. "(Fin de la cita, el subrayado es nuestro).

Respecto de la primera posibilidad deja en claro que ella se produce cuando un heredero transfiere el total o parte de la universalidad que comprende la herencia.

Respecto de la segunda, esto es, la cesión de cuota en un bien determinado, es tratada por el autor en un párrafo distinto y habla, específicamente, de ceder la cuota en un bien determinado dentro de una universalidad.

Los pormenores de cada uno de estos análisis no los reproduzco para no alargar esta nota.

Por último, todas las opiniones entregadas más arriba se encuentran avaladas por criterios jurisprudenciales, que me permito citar en apoyo a ella, (todas del repertorio): 
1) La transferencia de acciones y derechos, o sea de cuota, en un inmueble, necesita de inscripción en el Registro Conservador de Bienes Raíces;

2) La venta de derechos cuotativos, que un comunero tiene sobre un inmueble determinado que se precisa, no es cesión de derechos hereditarios que pueda quedar perfecta por la mera entrega del título sin necesidad de la inscripción; es venta de derechos en un inmueble cuya tradición debe hacerse con la inscripción;

3) Adquisición de una cuota en un bien determinado de la sucesión. El comprador adquirió sólo una cuota de un bien determinado y no los derechos en la universalidad de los bienes de la sucesión, no representa a los herederos del causante. En estas condiciones tiene únicamente una mera expectativa sobre la cuota adquirida por él, que queda sujeta al evento de que en la división de los bienes de la sucesión, se adjudique a los vendedores o cedentes, la cuota que les corresponde como herederos en ese objeto, de suerte que si la adjudicación de la parte alícuota que corresponde a estos herederos lo es en otros bienes de la sucesión y a todo derecho en este bien. 